\title{
Estudiantes, docentes y contexto educativo en la representación del profesorado en formación ${ }^{1}$
}

\author{
The Student, the Teacher, and the Educational Context in the Representation \\ of the Teacher in Training ${ }^{2}$
}

\section{Estudantes, professores e contexto educacional na representação dos professores em formaçãa ${ }^{3}$}

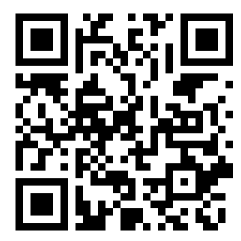

Gerardo Ignacio Sánchez-Sánchez

Universidad Católica del Maule

Talca, Chile

gerignsan@gmail.com

https://orcid.org/0000-0003-1694-1406

Ximena Elizabeth Jara-Amigo Universidad Autónoma de Chile

Talca, Chile

xjaraa@uautonoma.cl

https://orcid.org/0000-0001-7695-7579

\begin{abstract}
Recibido • Received • Recebido: 08 / 12 / 2017
Corregido • Revised • Revisado: 12 / 12 / 2018

Aceptado • Accepted • Aprovado: 02/ 05 / 2019
\end{abstract}

\begin{abstract}
Resumen: Esta investigación, situada en el contexto de una universidad regional que forma docentes, tiene como objetivo indagar en las representaciones que el futuro profesorado tiene de la figura de estudiantes, docentes y contexto escolar. Se optó por una metodología de tipo cualitativa. El trabajo se configuró en una zona de diálogo con 55 estudiantes de pedagogía en educación primaria que desarrollan sus procesos de práctica profesional en distintos contextos. A partir de la técnica de entrevista semistructurada, con aportes de relatos de vida, las personas participantes reportaron su experiencia. Los resultados muestran un trabajo docente complejo, por el cambio en el perfil estudiantil, que presenta clara oposición al concepto tradicional de autoridad y a una escuela que reproduce la dominación simbólica. También influyen en el resultado las tecnologías de la información y comunicación, que tensionan la comprensión de la tarea docente y la racionalidad con la cual esta se asume. El estudio abre un espacio de discusión para que la institución universitaria revise el proceso de formación del futuro profesorado y permite desarrollar las habilidades necesarias para una mejor inserción en contextos escolares con crecientes demandas.
\end{abstract}

Palabras claves: Práctica docente; representaciones; postmodernidad; autoridad; tecnología, Chile.

\footnotetext{
'Proyecto de mejoramiento institucional (PMI 1310). Centro de Investigación en Educación para la Justicia Social / CIEJUS.

${ }^{2}$ Institutional Improvement Project (PMI1310). Educational Research Center for Social Justice / CIEJUS.

${ }^{3}$ Projeto de Melhoria Institucional (PMI1310). Centro de Pesquisa Educacional para Justiça Social / CIEJUS.
} 
doi: http://dx.doi.org/10.15359/ree.23-3.8

URL: http://www.una.ac.cr/educare

CORREO: educare@una.cr

\begin{abstract}
This research, located in the context of a regional university that trains teachers, has the objective of studying the representations future teachers have of the student figure, the teacher, and the school context. We opted for a methodology of qualitative type. The work was set in a dialogue area with 55 elementary pedagogy students who develop their professional practice processes in different contexts. From the semi-structured interview technique, with life story contributions, the participants narrated their experience. The results showed a complex teacher's work, due to changes in the student profile, which represents clear opposition to the traditional concept of authority and to a school that reproduces the symbolic domination. The information and communication technologies (ICT) also affect the result: they put a strain on the comprehension of the teacher task and the rationality with which this task is assumed. The study opens a discussion space for the university institution to revise the formation process of future teachers, allowing developing the required skills for a better insertion in school contexts with increasing demands.
\end{abstract}

Keywords: teaching practices; representations; postmodernity; authority; technology; Chile.

Resumo: Esta pesquisa, localizada no contexto de uma universidade regional de pedagogia, tem como objetivo indagar as representações que os futuros docentes têm da figura do estudante, do professor e do contexto escolar. Optamos por uma metodologia de tipo qualitativa. O trabalho configurou-se em uma zona de diálogo com 55 estudantes de pedagogia do ensino fundamental, onde desenvolvem seus processos de prática profissional em diferentes contextos. A partir da técnica de entrevista semiestruturada, baseada em relatos de vida, as pessoas participantes reportaram sua experiência. Os resultados mostram um trabalho docente complexo, pela mudança no perfil de estudante, que apresenta clara oposição ao conceito tradicional de autoridade e a uma escola que reproduz a dominação simbólica. Também influem no resultado as tecnologias da informação e comunicação, que mostram tensões entre o entendimento da tarefa docente e a racionalidade com a qual este se assume. $O$ estudo abre um espaço de discussão para que a instituição universitária revise o processo de formação dos futuros profissionais docentes, permitindo desenvolver as habilidades necessárias para uma melhor inserção em contextos escolares com crescentes demandas.

Palavras-chave: Práticas docentes; representações; pós-modernismo; autoridade; tecnologia; Chile.

\title{
Introducción
}

\section{La sociedad posmoderna y la institución escolar}

El mundo ha estado cambiando de manera vertiginosa, experimentando así la aceleración del cambio social. Cambios en todas las esferas de la vida humana, desde la doméstica y terrenal, pasando por el desarrollo del ser y la vida espiritual. Las sociedades -al menos las occidentales globalizadas- tienen nuevas prioridades, la concepción de vida ha variado y las necesidades han evolucionado. El ser humano ha mutado por naturaleza. Esta realidad descrita se conoce historiográficamente como Postmodernidad (Vásquez, 2011). 
La transformación guiada por el afán de mejorar la forma en que se vive tiene, como una de las herramientas y característica esencial, la utilización masiva e intensiva de la tecnología y sus derivados; lo cual, necesariamente, tensiona la educación y los sistemas educativos en términos de demandas y dilemas; hace necesaria su reorganización y pone en discusión la capacidad de la escuela como institución social para seguir funcionando hoy día con la misma estructura y principios con los que operaba décadas atrás.

Coherente con la tradición normalizadora y disciplinadora, el carácter civilizador de la institución educativa "reforzó la ... inculcación ideológica de un universo cultural que se imponía a los sujetos como el único legítimo y, por lo tanto, negador de los universos culturales exteriores a la escuela" (Davini, 1995, p. 25).

En el escenario de las actuales transformaciones sociales, económicas y culturales, la escuela se ve tensionada, pues "el conjunto de las instituciones que caracterizaron la sociedad industrial están atravesando por profundas modificaciones, y que esto a su vez, muestra una sociedad que está reconfigurando sus dispositivos de control y reproducción social" (Tiramonti, 2004, p. 19).

En el contexto de estas modificaciones:

La relación docente-alumno, desarrollada en la modernidad, pierde vigencia en estos tiempos. Era una relación vertical, en la que el docente custodiaba la verdad y ejercía una transmisión unidireccional de conocimientos: la relación tenía a un maestro como dueño de la información, sin más recursos que una pizarra y una tiza, y a un alumno pasivo, como mero receptor. Este estilo pedagógico ya no encaja en la actual sociedad globalizada, con un entorno inestable y personalidades complejas. (Alfaro, 2011, p. 7)

Este cambio en la relación docente-estudiante, unido a la erosión de las instituciones, está a la base de la crisis de autoridad pedagógica, la cual históricamente se ha sustentado en la creencia de que "toda acción pedagógica es objetivamente una violencia simbólica en tanto que imposición, por un poder arbitrario, de una arbitrariedad cultural" (Bourdieu y Passeron, 1977, p. 45). En la actualidad, el profesorado no tiene asegurada la escucha, el respeto y la admiración de sus estudiantes como antaño. Desde la perspectiva de Fernández (2001):

Su palabra ya no es una revelación, sus decisiones pueden ser discutidas, su capacidad y su desempeño profesional llegan a verse cuestionados. Dicho en breve, el status -0 , si se prefiere, el prestigio- relativo del profesor, sobre todo del maestro, frente a su público, se ha deteriorado. (p. 72) 
doi: http://dx.doi.org/10.15359/ree.23-3.8

URL: http://www.una.ac.cr/educare

CORREO: educare@una.cr

El creciente reconocimiento de derechos de niños, niñas y adolescentes obliga al profesorado y a la institución educativa a "transformar sus dispositivos, en especial aquellos que regulan las relaciones de autoridad entre profesores, directivos y alumnos, las que organizan el orden y la disciplina y aquellas que estructuran los procesos de toma de decisión" (Tedesco y Tenti, 2002, pp. 11-12).

Desde los planteamientos de Pérez, Martínez, Tey, Essombra y González (2007): “Dentro de la evolución vertiginosa de la sociedad y de la cultura que ha instalado disparidad y heterogeneidad en las situaciones y en los contextos" (p. 13), la obsoleta escuela decimonónica con un afán en la transmisión homogénea de contenidos, y el tratamiento uniforme de estudiantes "debe cambiar absolutamente en su organización interna, en sus relaciones con la sociedad, en sus funciones educativas, en las funciones de los docentes, en la forma de agrupar a los escolares, en la apertura del centro a la sociedad" (March y Orte, 2014, p. 22). El desafío no es menor para una institución que se va "desinstitucionalizando cada vez más perdiendo su legitimidad como espacio único" (Dubet, 2010, p. 222).

En la práctica, enseñar se complica, entre otras cosas, por lo siguiente:

Porque esos otros, que son niños y jóvenes, suelen resistirse a la intervención adulta y también muchas veces a la escuela; una escuela cuya institucionalidad o forma de imponer/socializar/educar se halla debilitada o resquebrajada; una escuela cuya forma predominante no condice con los modos de comunicación y socialización dominantes fuera de ella. (Alliaud, 2017, p. 30).

En consecuencia, ser docente en el siglo XXI implica asumir que el conocimiento y el estudiantado cambian velozmente, y que para dar respuesta adecuada y satisfacer el derecho de aprender del estudiantado, se hace fundamental que el profesorado continúe aprendiendo las teorías, metodologías, técnicas y prácticas que el alumnado de hoy necesita. De acuerdo con los aportes de Toffler (1990), la educación postmoderna necesita intensa interactividad, movilidad y democratización de la información, si lo que pretende es educar para convivir con el cambio. Desde la perspectiva de Hargreaves (1994), "el mundo postmoderno es rápido, comprimido, complejo e inseguro" (p. 37).

Estos requerimientos se contraponen fuertemente a las funciones de la escuela moderna, la que, con un modelo de cultura y civilización europea, tiene como resultado un aparato pedagógico regulado por la práctica del orden y control escolar: "La práctica de ordenar, licenciar y regular que estructura la educación pública se funda en un temor a la diferencia y la indeterminación" (Giroux, 1996, p. 7). 
El desafío para el profesorado es visualizar cómo están surgiendo nuevas y diferentes identidades en ámbitos que las escuelas generalmente pasan por alto. Lo anterior obliga a revisar la racionalidad con la cual opera la escuela y la formación inicial docentes.

En términos generales, la formación del profesorado ha girado en torno a una tradición que "establece una clara distinción entre conocimiento teórico y conocimiento práctico, y entiende al segundo como una aplicación del primero" (Diker y Terigi, 2008, p.115). Sin embargo, al enfrentarse a los requerimientos del aula constata que las limitaciones de la racionalidad aplicacionista requieren una formación orientada a "comprender la compleja realidad educativa y construir modos de actuación inscritos en ella a la vez que transformadores, así como de incluir dispositivos que los aproximen de manera gradual pero irrenunciable a las escuelas y al ejercicio del rol" (Diker y Terigi, 2008, pp.122-123).

Enfrentada a las nuevas demandas que se derivan de la sociedad postmoderna, la institución formadora debería ser parte del proceso de transformación; sin embargo, las instituciones de formación del profesorado parecen presentar fuertes limitaciones para responder a las nuevas demandas. Se cuestiona su burocratización, su orientación teórica, su organización parcelada del conocimiento y su escasa vinculación con el territorio de las escuelas (Marcelo, 2009).

\section{Referentes nacionales y teóricos en torno a la formación para la práctica}

Entre los principales desafíos que enfrentan las políticas educacionales se encuentra el mejoramiento de la formación inicial docente (FID), se reconoce el rol fundamental que profesionales de la educación tienen en el desarrollo de un sistema educativo de calidad. En ese escenario, se entienden los esfuerzos orientados a potenciar la formación práctica del futuro profesorado.

La formación práctica debe ser considerada como parte del plan de estudios y articularse de manera sistemática a lo largo de toda la carrera, de acuerdo con lineamientos que contemplan: (a) la incorporación formal de toda la formación práctica en el plan de estudios; (b) prácticas tempranas y progresivas durante todo el ciclo de formación profesional en diversos contextos territoriales, socioeconómicos y culturales; y (c) práctica final, que asegure los conocimientos, habilidades y competencias requeridas para el ejercicio de la profesión docente.

Para ello, las universidades que imparten carreras de pedagogía han de asegurar una permanente articulación con el sistema escolar, a través de la formación práctica. Esta vinculación permite que confluya el enfoque educativo de la universidad; los propios procesos de construcción profesional de estudiantes; y el establecimiento educacional como sistema complejo que ofrece oportunidades de formación.

En Chile, los trabajos desarrollados en torno a la formación inicial docente (Ávalos, 2003; Cisternas, 2011; Labra, 2011; Latorre, 2006; Montenegro y Fuentealba, 2012) confirman que los procesos de práctica que desarrollan el futuro profesorado chileno se conciben como una 
doi: http://dx.doi.org/10.15359/ree.23-3.8

URL: http://www.una.ac.cr/educare

CORREO: educare@una.cr

actividad de transmisión de datos, difusa, descontextualizada y muy uniforme; caracterizada por una fuerte fragmentación de los contenidos y una constante desvinculación del proceso formativo respecto de los reales requerimientos del medio escolar.

Ahora bien, si las prácticas, desde la perspectiva de Ávalos (2003) "tienen como objetivo facilitar el proceso por el cual los futuros profesores construyen conocimiento pedagógico, desarrollan en forma personal teoría y práctica de la enseñanza y el aprendizaje y, sobre todo, aprenden a enseñar" (p. 109), un programa de formación inicial que intente relevar la práctica, debería articularse sobre la base de una relación dialéctica entre teoría-práctica, mediada por la investigación; un escenario de relaciones dotado de sentido entre la universidad y los centros escolares; la relevancia del trabajo colaborativo en las prácticas; y una nueva mirada a la posición de la persona practicante (Sayago y Chacón, 2006).

Enfrentando la tarea de aprender a enseñar, es preciso reconocer el carácter dinámico y evolutivo del proceso a lo largo del tiempo:

La formación inicial no concluye con el objetivo de haber enseñado las herramientas básicas de la profesión, sino que éstas se adquieren durante los primeros años de enseñanza en el contexto de la práctica. Tercero, porque los esquemas de actuación profesional no aparecen de la nada con el inicio de la enseñanza, sino que se van conformando a través de las experiencias prácticas, preformativas y de formación inicial. (Fernández, 2008, p. 68)

Profundizando en la problemática, es preciso reconocer que cuando se viven los procesos de práctica los esquemas de actuación avanzan desde una percepción situacional reducida a una visión intuitiva de las situaciones de enseñanza basada en una comprensión más profunda. Desde esa percepción parcial de la realidad, enfrentan la práctica y la complejidad del trabajo docente. El desafío de la formación inicial debería orientarse a "familiarizar al aprendiz con unos juegos de reglas flexibles y cambiantes, en protegerlo frente a la ilusión de la explicación teórica todopoderosa, falaz e indispensable por el hecho de ser parcial y estereotipada" (Carbonneau y Hétu, 2010, p. 123).

En ese sentido, familiarizar al estudiantado con el ejercicio de la docencia implica indagar en las representaciones que va construyendo durante sus prácticas, entendiendo que las representaciones constituyen "instrumentos cognitivos de aprehensión de la realidad y de orientación de las conductas sobre lo que significa ser profesor" (Baillauquès, 2010, p. 55).

\section{Objetivo de investigación}

El objetivo que persigue este estudio es indagar en las representaciones que el profesorado en formación desarrolla de la figura del estudiantado, el profesorado y las características del contexto escolar las que en definitiva configuran la labor educativa. 


\section{Metodología}

Este capítulo informa parte de la investigación Los docentes en formación y la comprensión de sus experiencias pedagógicas (Sánchez, 2016-2017), desarrollada en el contexto de la Facultad de Ciencias de la Educación. La presente comunicación tiene la intención de mostrar las representaciones en torno al estudiantado, el profesorado y el contexto educativo desarrolladas, por estudiantes de pedagogía en práctica profesional.

Setrabajócon55estudiantes deeducación primariaquienesofrecieronsusrepresentaciones respecto a la experiencia de práctica desarrollada. De este grupo, 45 corresponden a mujeres y 10 varones, con edades que oscilan entre los 23 y 30 años. Los criterios para elegirles fueron:

- Estar cursando el último semestre de la titulación.

- Aceptaran participar de forma voluntaria, tras firma de consentimiento.

Se optó por un abordaje de tipo cualitativo, para recuperar algunos insumos del paradigma de la narrativa en ciencias sociales que valoran al sujeto como actor de su propio proceso formativo. El diseño utilizado fue de tipo transeccional no experimental con un nivel de profundidad exploratorio-descriptivo (Hernández, Fernández y Baptista, 2010), a través del método de estudio de casos interpretativo (Pérez, 2007).

El abordaje metodológico requirió una aproximación de carácter intensivo mediante el uso de una entrevista semiestructurada (Flick, 2007) a profesionales en formación, la cual permitió indagar en torno a la noción del trabajo docente, las imágenes sobre el estudiantado de educación primaria, el profesorado y los cambios en el contexto donde se desarrolla la docencia. Se dispuso el uso de esta aproximación metodológica, con guión de preguntas previamente validado, la que permitió acceder a datos descriptivos y a un abordaje interpretativo de los sujetos investigados.

Se utilizó la técnica de análisis de contenido (Ruiz, 2009), a partir de tres operaciones claves, a saber: una primera fase de reducción de datos en que se selecciona y organiza la informacíon para hacerla más abordable con la asignación de un código asociado a la inicial del nombre y un número correlativo a cada una de las entrevistas previamente transcritas; una segunda fase de reducción de datos a partir del levantamiento inductivo de categorías acompañado de la evidencia empírica correspondiente; y una tercera fase de obtención de resultados y conclusiones que facilitan nuevos elementos y compresiones relacionados con la temática investigada. 
doi: http://dx.doi.org/10.15359/ree.23-3.8

URL: http://www.una.ac.cr/educare

CORREO: educare@una.cr

\section{Resultados}

Las categorías de análisis que surgen de las entrevistas a los sujetos (Tabla 1) dan origen a los siguientes resultados.

Tabla 1: Categorías de análisis

\begin{tabular}{ll}
\hline Categoría & Unidad de análisis \\
\hline 1. Labor docente & $\begin{array}{l}1.1 \text { Integralidad de la formación } \\
1.2 \text { Fenómeno de autoridad }\end{array}$ \\
\hline 2.Perfil del estudiantado de primaria & 2.1 Nuevo perfil estudiantil \\
& 2.2 Relación con la escuela \\
\hline 3. Cambio en el territorio & 3.1 Tecnología \\
& 3.2 Diversidad \\
\hline
\end{tabular}

Nota: Elaboración propia, tomando en cuenta entrevistas aplicadas.

\section{Labor docente: El ayer y el hoy}

\section{Una tarea comprometida en su intención con una formación integral fuertemente tensionada}

Enfrentado al desafío de enseñar, los procesos de práctica ponen al estudiantado de pedagogía en el escenario de contrastar sus proyectores conceptuales construidos como producto de sus experiencias preformativas en su paso por la escolaridad, con las demandas planteadas por la formación inicial en torno al deber del ejercicio profesional, para, desde ahí, arribar a una noción más situada de la tarea docente en un proceso de fuerte implicación, según el cual entramos en una relación afectiva con nuestro objeto de trabajo. Se refuerza la íntima conexión entre las imágenes/expectativas del oficio y las realidades de este último.

En ese proceso, los relatos refieren a un trabajo docente comprometido con la integralidad de la formación

... La tarea del profesor es formar seres integrales. Los cuáles serán los ciudadanos del país del mañana, serán los líderes y los responsables de la sociedad. Es en ese momento en que realmente somos conscientes de la importancia de la labor docente, la que va mucho más allá de solo transmitir conocimientos, puesto que se forma al niño, se contribuye a desarrollar su personalidad. (EL13) 
... Un buen profesor para lograr aprendizajes en sus estudiantes, necesita estar atento a las necesidades que surgen en ellos, debe conocerlos, modificar sus estrategias para lograr un aprendizaje para la vida, es decir integral. (EM7)

La tensión que se genera frente a la concreción de la idea de integralidad, radica en la presencia de una escuela que sigue anclada en la modernidad, que se resiste a entender y asumir las demandas que se derivan de la presencia de sujetos actores que exigen una nueva relación pedagógica, y que se manifiestan desde un fuerte cuestionamiento en torno a aquello que la escuela ofrece, en términos de objetivos, espacios y tiempos.

... Enseñar hoy día resulta una tarea ardua, pues hay que operar en distintos frentes. Por una parte, preocuparse por lo académico logrando aprendizaje en los estudiantes, por otra parte, estar atento a sus necesidades y motivarlos para que se interesen en los contenidos. Y por si fuera poco, hacerse cargo de la formación valórica, pues en la actualidad las familias no están muy preocupadas y le dejan todo el trabajo a la escuela, a los profesores. (EL1)

... La escuela en que me formé era muy distinta, primaba en ella el orden, la disciplina y el respeto. En ella los profesores representaban el conocimiento y la posibilidad de salir adelante y ser mejor. Hoy en cambio, poco o nada de ello parece tener sentido para los estudiantes y sus familias. (ECN4)

En el siguiente extracto, se explicitan las diversas demandas planteadas al ejercicio de la docencia,

... La labor docente hoy en día es casi la de padre. Ellos son los que deben enseñar al niño, cuidar, apoyar, corregir, guiar y sostenerlos cuando necesitan mejorar su estado anímico. El profesor de hoy trata de cumplir todos esos roles y aún más imparten conocimiento y contenidos. En fin, trata de cumplir roles que no le corresponden. (EL19)

Los próximos relatos reparan en la profundidad de la tarea, expresada en la metáfora del iceberg:

... Una clase solo es la punta de un iceberg, es el producto de todo un trabajo previo. Un trabajo que requiere de mucho tiempo, dedicación, pasión, creatividad y la tan mencionada vocación de un profesor, y eso lo descubrí con la práctica. Creo que la labor que ejercen los docentes no es fácil, que es una de las tareas más complejas por todo lo que involucra, porque no es menor enseñar para la vida, enseñar a ser, aparte del saber y del saber hacer. (EM12) 
doi: http://dx.doi.org/10.15359/ree.23-3.8

URL: http://www.una.ac.cr/educare

CORREO: educare@una.cr

... Pensar, discutir, analizar y tomar decisiones respecto a un estudiante para ayudarlo, mantener una comunicación con las familias, un diálogo en común con los demás profesores para alcanzar las metas, estar constantemente capacitándose para estar al día y realizar un buen trabajo, son una de las tantas tareas que acompañan al ejercicio docente y que no siempre son tan visibles. (EL15)

La complejidad aparece fuertemente asociada a las características del escenario sociocultural en que se desenvuelven los sujetos, y que condiciona las posibilidades educativas planificadas desde la escuela y por esta.

... El internet no era accesible en todos los hogares, por lo que no existía esa impetuosidad de quererenfrentara los profesores cuestionandosu verdady poniendo a pruebasu conocimiento, como muchas veces pasa hoy en día, en donde los niños son nativos de la tecnología y debaten su postura interpelando al profesor. (EL16)

Ese escenario sociocultural ve el surgimiento de un nuevo perfil de estudiantes, cuyas particularidades demandan contención y movilización por parte del profesorado, para asegurar aprendizaje.

... Sé con certeza que el trabajo de profesor no es siempre grato, que hay muchas dificultades y de ellas, quizás la más grande, es enfrentar las diferentes personalidades que hay dentro del aula. Personalmente el desafío más grande que estoy viviendo en la práctica es intentar conocer las personalidades de todos los estudiantes, que no se muestran muy interesados en lo que se les enseña, que le cuesta concentrarse en la tarea. (EL18)

Diversidad del estudiantado que demanda del profesorado, la movilización de una serie de características y disposiciones personales:

... La simpatía, amabilidad, confiabilidad y diversión son medios por los cuales el docente puede llegar a trascender en sus alumnos, creando un lazo de respeto y confianza con ellos, y de esa manera ayudar en el cumplimiento de los objetivos propuestos. (EL5)

Finalmente, la complejidad del trabajo aparece tristemente tensionada por la escasa valoración social de la labor desarrollada por docentes:

... Pese a la importancia que tiene, no es valorada. Es una carrera mirada en menos, sobre todo por el sueldo. Menciono esto, porque mi tesis anterior trataba de las percepciones que tenían los estudiantes sobre la profesión docente. Para eso se realizaron entrevistas a 300 estudiantes de distintos establecimientos y la gran mayoría valora la profesión docente, la ven como un trabajo sacrificado que requiere de tiempo y dedicación, pero con salarios bajos. (EL8) 


\section{El fenómeno de la autoridad docente experimenta transformaciones en el tiempo}

Emerge la noción de autoridad anclada a un marco temporal que ya no existe, evocando la figura de profesores y profesoras que se han caracterizado por marcar presencia, disciplina y temor en su vínculo con el estudiantado.

Este sentido de la autoridad, queda reflejado en los siguientes fragmentos de entrevista:

... Un niño ve entrar a la sala de clases al profesor con una autoridad definida, lo observa hacer su clase y luego irse, no olvidando mencionar el orden que intenta mantener en la sala para que los niños no se alboroten tanto. Por lo tanto, cuando éramos niños solo veíamos esta parte de la historia, el profesor que viene a hacernos clases. (EL5)

... Solo pensaba en que era una figura de autoridad, a la que debíamos respetary obedecer. (EL12)

Expresiones como "autoridad", "respeto", "exigencia", "entrega", "compromiso", "energía"; ocuparon centralidad en los relatos al momento de caracterizar la figura del profesorado.

En muchos de los relatos, emerge una representación que añora la noción de autoridad, según la cual la presencia del profesorado exige un respeto por su condición de adultez, de autoridad.

... Los docentes se limitaban a pasar el contenido sin importar mucho si todos los estudiantes aprendían y de qué manera estos lo hacían. No existía una diferencia con los estudiantes que tenían alguna necesidad educativa especial, sino que se les trataba mal y poco menos eran alumnos "cacho", que simplemente si les iba mal quedaban repitiendo. (EL11)

Asimismo, en la siguiente cita, se pone de manifiesto el componente vicario que encierra la actuación del equipo docente, respecto a la fuerza/energía para ejercer influencia en la relación autoridad-coacción:

... La figura del docente representaba y proyectaba muchas cosas. En primer lugar era un modelo, una figura inquebrantable, capaz de ser un dictador en la clase y sobre lo cual existían muy pocas posibilidades de diálogo. En pocas palabras siento que me formé bajo una mirada de profesor que precisaba un manejo y control absoluto de curso, en donde prevalecía la norma y el carácter por sobre la paciencia y la empatía. (EN3)

Mirado en perspectiva, la autoridad del equipo docente se muestra ambivalente. Su visión tradicional resulta cada vez más ausente del aula actual, pese a que se la busca y añora.

... Los veía como una autoridad, a algunos se les toma aprecio, mientras que a otros se les aborrece, pero no pasan desapercibidos. (EN7) 
doi: http://dx.doi.org/10.15359/ree.23-3.8

URL: http://www.una.ac.cr/educare

CORREO: educare@una.cr

... Tradicionalmente la figura del profesor no admitía duda ni mucho menos cuestionamiento. Lo que el profesor decía era ley, se lo respetaba. Nadie osaba cuestionar sus actuaciones. (EN5)

Esta autoridad se encuentra asociada a su condición de docente, y respaldada en su dominio de lo que enseña y el control disciplinario de los grupos, como lo plantea la siguiente cita:

... Ve al profesor como la persona que debe enseñar "algo". En micaso personal veía al profesor como el personaje que debía hablar toda la clase y responder a las preguntas que podían surgir de los estudiantes, manejando la disciplina y buscando siempre la selección. (ES7)

Los fundamentos de la autoridad han estado tradicionalmente asociados a la coacción y aparecen fuertemente tensionados por el desafío actual de persuasión, como modo de ejercer influencia.

... El significado de ser profesor lo lleva aquel capaz de imponer orden para que el proceso de enseñanza se desarrolle con normalidad. (ES5)

... Hoy para míla concepción del profesor del siglo XXI es aquella que lo estipula como el pilar de esta sociedad, ese ser capaz de impactar nuestra mente y guiar nuestro desarrollo. Una persona que es capaz de motivar a sus estudiantes, que busca convencer más que imponer sus decisiones. Capaz de dialogar con los estudiantes y construir acuerdos. (EN3)

\section{El perfil del estudiantado de primaria}

\section{El cambio en las personas actoras: El nuevo perfil del estudiantado}

El alumnado no es el agente pasivo del proceso de enseñanza-aprendizaje, por el contrario, y coherente con lo que reporta la teoría, el estudiantado actual es inquieto, más informado, con intereses e inquietudes propias, dispuesto y capacitado para enfrentar, apoyar y cooperar en su propio proceso de enseñanza-aprendizaje, pero también capaz de ofrecer resistencia al proceso que se le presenta, demandando por el sentido y proyección.

Desde el punto de vista de la potencialidad de este perfil, se destaca, en este, el que suele ser interactivo, espontáneo, hábil en el uso de las tecnologías y ávido de experiencias y sensaciones

... Ellos son los que están creciendo en este tiempo, con las condiciones del mundo actual, son una generación que tiene acceso a muchas cosas, las que si son bien usadas les permite desarrollarse positivamente. Son niños digitales, saben utilizar los medios de comunicación a cabalidad, poseen un aprendizaje práctico y rápido. (EL4) 
... El cambio en el comportamiento de los estudiantes ha sido contundente y este se nota fundamentalmente en cómo estos aprenden... son estudiantes que no se conforman con escuchar al profesor, esperan actividades dinámicas y más vinculadas con la realidad. (EL9)

De lo negativo, su actitud desinteresada y contestataria emerge con fuerza en el próximo relato,

... Ahora los niños tienen otro comportamiento y están preocupados de otras cosas que muchas veces no corresponden a su edad. También he observado lo inquietos que son y que hay un gran porcentaje de estudiantes que toma pastillas para controlarse, debido a que no pueden quedarse tranquilos y están haciendo desorden durante las clases. Los niños de hoy son dispersos y tienen una personalidad disruptiva, ya no tienen temor al profesor, al contrario son desafiantes. (EL3)

Para el profesorado en práctica, la relación con este nuevo perfil resulta problemática en lo referido a equilibrar libertad-control, pues, muchas veces, son difíciles de contener y motivar, tienen reacciones muy inesperadas.

... Como docentes debemos desdoblar esfuerzos por encantar a los educandos, debiendo innovar constantemente, pues ellos han nacido en la sociedad de lo desechable, pues cada recurso y metodología debe ser diversa, y por sobre-todo apuntar a sus intereses personales. (EL5)

... Ahora los estudiantes son más confrontacionales, el respeto hacia sus profesores no es el mismo, hoy en mi práctica profesional, la cual realizo en un liceo municipal con alta vulnerabilidad emocional de los estudiantes, he visto como estos les gritan, levantan la voze ignoran a sus profesores. Los estudiantes no poseen ninguna motivación intrínseca, no tienen ningún objetivo y tampoco les preocupaba tenerlos, ellos solo viven el día a día intensamente, creyéndose dueños del mundo, son niños jugando a ser grandes; entonces como "supuestos adultos" no quieren regaños de nadie y solo quieren hacer lo que a ellos les gusta, y lamentablemente asistir a escuelas, colegios o liceos no está dentro de sus prioridades. (EL7)

Elactor actual se proyecta distinto al de antaño, en sus formas de interacción y socialización.

... Los chicos de años atrás jugaban a la pelota, a las bolitas, a la escondida, al pillo, entre tanto otros, y hoy como ya se mencionó, pasan su tiempo libre viendo videos de juegos, jugando, chateando y visitando sitios de internet no pertinentes ni acordes a su edad. (EL19)

En consecuencia, emerge un nuevo perfil de estudiante que comienza a tensionar las bases en que se construyó la institución escolar. Desde el punto de vista de sus características asistimos al tránsito de un estudiantado tranquilo y ante todo respetuoso del orden establecido a otro 
doi: http://dx.doi.org/10.15359/ree.23-3.8

URL: http://www.una.ac.cr/educare

CORREO: educare@una.cr

hiperactivo y rebelde, muy consciente de sus derechos y de lo que no espera encontrar en el aula. Sus entretenciones transitan desde la modernidad representada por el juego real, de contacto personal, al juego virtual que encuentra en internet y es representado por los videos juegos.

\section{Relación con la escuela y su institucionalidad}

El profesional en práctica constata que la relación del nuevo estudiante con la escuela se configura desde la resistencia a una autoridad vertical y a una institución que no constituye un espacio natural, sino mediado por una obligación que se siente y que condiciona sus márgenes de libertad. El nuevo estudiantado entiende los códigos de la tecnología y, refugiado en ella, ofrece resistencia al proyecto de enseñanza que se le intenta presentar.

En ese sentido, la figura de autoridad tradicional del docente y la docente se debilita, y tiende a dejar al profesorado perplejo sin capacidad de reacción ante un escenario en que la palabra de este deja de ser ley, más allá del rechazo a este nuevo escenario, que reconfigura la relación de los sujetos actores del proceso educativo: docentes y estudiantes. Llama la atención que, para el profesorado y la escuela, este nuevo escenario constituye ante todo una amenaza y no logra ser percibida como oportunidad para transformar la escuela y, con ello, la sociedad, en una educación más conectada con la vida.

Observan la presencia de una escuela cuya institucionalidad anclada en la modernidad se enfrenta a un estudiantado postmoderno, con el cual no logra sintonizar y sin darse cuenta de su persistencia en la misma racionalidad que intentan superar, termina por generar más desinterés y resistencia, que compromiso por parte del nuevo perfil que arriba a ella.

... Cada día los estudiantes se muestran más reticentes a lo que el profesor les pide u ofrece. Particularmente en el segundo ciclo son contestatarios y parece que nada los motiva, todo lo encuentran aburrido y in sentido. Les resulta difícil asumir sus deberes como estudiantes y más preocupados por sus derechos. Encuentro que cada año los problemas de disciplina y convivencia aumentan y hacen difícil el trabajo de los profesores y el funcionamiento de la escuela. (EL5)

\section{El cambio en el territorio}

\section{La presencia de una sociedad tecnológica}

El marco sociocultural que rodea la escuela actual es un territorio que se configura a partir de situaciones sociales definidas como concreciones en el espacio y el tiempo de una estructura social, percibidas y vivenciadas por el sujeto, constituyendo un repertorio de posibilidadeslimitaciones educativas. En el escenario actual, la complejidad del factor tecnológico, configura una serie de implicancias para los procesos de enseñanza aprendizaje. 
Desde la perspectiva del profesorado en práctica, este factor tecnológico constituye abiertamente una situación limitante (inhibidora) del trabajo docente y de la educación misma, en tanto lo dificulta, limita y entorpece. Los relatos manifiestan las dificultades del profesorado para convivir con la tecnología y convertirla en un factor de posibilidades educativas en su trabajo; por el contrario, la conciben en parte también responsable de la crisis ética que presenta la familia y la sociedad, sin reparar en lo que la escuela hace o deja de hacer para transformar esa realidad.

... Soy de la generación de la tecnología, del celular, del mp4, internet, etc. Sin embargo, estos aparatos y las clases no compatibilizaban, es decir, ni pensar que en la clase de lenguaje por ejemplo, para escribir algún texto, mientras lo hacíamos podíamos escuchar música, o que para resolver alguna guía de ejercicios en matemáticas podíamos realizarla con el celular. (EL13)

... Un factor que creo que hace que los estudiantes del hoy no sean igual que los de ayer, es que el ingreso y la modernización en el aspecto tecnológico, ha sido muchas veces un enemigo a la hora de poder realizar las clases, debido que ya la gran mayoría, para no decir todos los estudiantes poseen celular, estos los llevan a todas partes y no creo que sea por alguna urgencia, sino que por estar conectado a las redes sociales. (ES10)

El profesorado en formación advierte con claridad la existencia de un marco sociocultural distinto, que se explica por los procesos de globalización y el avance en las tecnologías de la información y comunicación. Los relatos se plantean en términos de:

... Quién iba a imaginar a niños de primero o segundo básico con teléfonos celulares, con una red de comunicación que permite que otros sepan de todo acerca de ellos, como el caso de Facebook, donde incluso pueden estar expuestos al peligro por el mal uso de las nuevas tecnologías. (EM8)

... Los pasatiempos o los hobbies y juegos también han cambiado. Hoy en día los intereses de los niños están en los vídeos juegos, lecturas de sagas y pasargran tiempo frenteal computador. Son estudiantes tecnológicos con influencias de la televisión en sus comportamientos: imitan a personajes de series animadas, en ocasiones agresivos, debido a la cantidad de violencia que se exhibe hoy en día en los programas televisivos. (EL16)

Las tensiones entre aprender y entretenerse, se manifiestan en el relato que se presenta:

... Estos cambios podrían englobarse en que los niños ya no se sienten motivados ni interesados a aprender, puesto que consideran mucho más fácil y entretenido ver televisión, jugar videojuegos, navegar en internet, subir vídeos, y mantener al día su cuenta de Facebook que interesarse y encontrar placer al aprender algo por su cuenta, que de verdad les va a ser útil en su vida adulta. (EL13) 
doi: http://dx.doi.org/10.15359/ree.23-3.8

URL: http://www.una.ac.cr/educare

CORREO: educare@una.cr

... Desdeel profesory los libros como mecanismos de acceso a la información yel conocimiento a la red. Hoy, en cambio, todo está en la red; increíble y maravillosamente todo gira en la bola de cristal llamada ciberespacio, lo que si bien ha facilitado la búsqueda, también está haciendo crecer niños, jóvenes y adultos dependientes que carecen de técnicas de búsqueda, recopilación, organización, síntesis y sobre todo crítica y reflexión. (EM1)

En este territorio, el componente ético define una familia que ha cambiado su visión respecto a la escuela, al sentido de la formación y las propias responsabilidades

... Los padres jugaban un rol fundamental en el comportamiento de los estudiantes, pues tenían la imagen de autoridad frente a ellos y cualquier falta que cometieran sabían que serían castigados. Los padres de ahora son más relajados y permisivos, lo que provoca que los hijos no los vean autoritarios y por lo mismo les desobedecen y muchas veces contestan de una forma poco apropiada y eso es lo que posteriormente se refleja en el aula, en donde no se dan cuenta que hay que respetar a las personas mayores, que en ese contexto sería el profesor. (EL3)

\section{La presencia de una sociedad crecientemente diversa}

Un aspecto que reconfigura la actuación docente está dado por la convicción según la cual el profesorado de hoy debe desempeñarse en un entorno más diverso en cuanto a las características de sus estudiantes, es decir, su personalidad, formas de aprender, valores y principios:

... Ahora estoy del otro lado del escritorio, personalmente el desafío más grande que estoy viviendo en la práctica es intentar conocer las personalidades de todos los estudiantes, que no responden con el mismo interés y actitud frente a las propuestas pedagógicas. (EN7)

... En una sala de clases no todos entienden de la misma manera, ya que hay gran diversidad haciendo difícil captar el interés en lo que se les enseña. Muchos de ellos no tienen la intención de aprender, otros se distraen con facilidad y la gran mayoría se dedica a generar resistencia e indisciplina. (EL15)

... Se con certeza que el trabajo de profesor no es siempre grata, que hay muchas dificultades y de ellas, quizás la más grande, es enfrentar las diferentes personalidades que hay dentro del aula. (EM9)

La sociedad globalizada se caracteriza cada vez más por su diversidad, sin embargo, trabajar con la diversidad es un desafío que nuestros sistemas educativos manejarían con dificultad, situación que refleja bien el profesorado que comienza a enfrentar el trabajo docente. 


\section{Conclusiones}

El profesorado en formación, enfrentado al proceso de práctica, ¿está preparado para un trabajo donde el perfil de estudiantes se caracteriza por una creciente diversidad y anclado al uso de la tecnología, tensiona la racionalidad que ha definido al trabajo docente y a la institución escolar? Los resultados de la investigación confirman la presencia de una trama del trabajo docente que tiende a tornarse progresivamente compleja y que resulta difícil asumirla con efectividad. Compleja en cuanto al cambio en el perfil estudiantil al que se enseña y que ofrece claras resistencias al concepto tradicional de autoridad con que opera el profesorado, cuestión no menor considerando que la "autoridad pedagógica, entendida como reconocimiento y legitimidad sigue siendo una condición estructural necesaria de la eficacia de toda acción pedagógica" (Tedesco y Tenti, 2002, p. 12). Compleja también en lo referido al influjo que ejercen las tecnologías de la información y comunicación, las cuales tensionan la comprensión de la tarea docente y la lógica con la cual esta ha sido regularmente planteada.

Como lo señalan los resultados y lo confirma la teoría, las instituciones de formación del profesorado parecen estar fuertemente limitadas para responder a las nuevas demandas, dado su carácter excesivamente teórico, su organización fragmentada del conocimiento y particularmente por la naturaleza de este trabajo, la escasa conexión con las escuelas (Marcelo, 2009).

En tal sentido, los relatos del profesorado en formación aluden a la presencia de un nuevo actor -el estudiantado de aula considerado ahora persona sujeto de derechos- que muestra oposición a la presencia de una escuela cuyo cometido sea reproducir la dominación simbólica, el no aceptar de manera pasiva dicha dominación evidencia que no todos los actores se conforman con la lógica dominante.

Lo anterior, según el relato de la mayoría del profesorado en formación, tiende a tensionar la racionalidad de una escuela que, en su afán de dominar y controlar, define roles que tanto docentes como estudiantes "deben" desempeñar para promocionar y resguardar su funcionamiento y cometido.

Desde la perspectiva del profesorado en formación -representantes de la institución formadora y de la institución escolar- se visualizan las nociones de conflicto, lucha y resistencia a las demandas planteadas por el nuevo perfil del estudiantado. Más allá de las tensiones que genera al sujeto practicante, el alumnado de la escuela de hoy muestra una participación activa a través de conductas de oposición o resistencia frente al carácter de disciplina y nivelación con que actúa la institución educativa (Giroux, 1996). En tal sentido, la tecnología constituye un elemento de resistencia desde el cual el estudiantado de aula tiende a desarticular la presencia de una escuela que no responde a sus intereses, sin dimensionar probablemente que en la tecnología también se esconden mecanismos de dominación, que permean, directamente, la sociedad en los distintos espacios de socialización y como parte de las influencias del contexto sociocultural en que se desarrollan niños, niñas y adolescentes. 
doi: http://dx.doi.org/10.15359/ree.23-3.8

URL: http://www.una.ac.cr/educare

CORREO: educare@una.cr

Observamos la dificultad que en la actualidad experimenta el profesorado para armonizar sus acciones con las del estudiantado, que hoy se muestran activo y dispuesto a ofrecer resistencia a las diversas iniciativas definidas por sus docentes. Este profesorado tiene serias dificultades para entender que el nostálgico orden no corresponde a una cualidad ontológica de las situaciones. Como lo sostiene Tardif (2004), el profesorado en formación enfrenta el desafío de lograr en sus estudiantes una "sujeción voluntaria" y comprometerse con la búsqueda de acciones que hagan posible el interés por aprender.

De lo anterior surgen dos tipos de consecuencias. En primer lugar, el reconocimiento de un trabajo docente constituido por tensiones y dilemas, pues su relación con el alumnado está constituida fundamentalmente por relaciones sociales, que obligan al despliegue de negociaciones e interacciones. En segundo lugar, la ausencia de un control total ejercido por docentes sobre estudiantes, lo que dificulta el trabajo y el logro de objetivos en la práctica.

Es posible concluir en relación con la formación inicial, que el estudiantado de pedagogía enfrenta la práctica, a partir de ciertos proyectores conceptuales e imágenes preformativas (Carbonneau y Hétu, 2010), desde los cuales desarrolla una percepción de la realidad, y como estos proyectores son aún insuficientes cuando se enfrenta al trabajo en aula constata el choque con la realidad: el alumnado no se comporta como estaba previsto, cómo "debería" y se manifiesta muy distinto en su perfil y actitud hacia el aprendizaje; la tecnología que acompaña a este estudiantado dificulta el desarrollo de un proceso anclado en el conocimiento y el texto escolar; la autoridad profesoral se ve cuestionada y demanda la definición de nuevos pactos en la relación con sus estudiantes.

En ese escenario, la escuela se constituye en el espacio que juega una relación contradictoria con la sociedad imperante, alternativamente sus docentes juegan el papel de apoyo a ese modelo de sociedad; y sus estudiantes el de crítica y resistencia. En suma, una institución que expresa en su accionar, las tensiones y problemas de nuestra época en lo que a posibilidad educativa se refiere.

En medio de la turbulencia del territorio, el profesorado en formación experimenta la práctica a partir de una imagen del estudiantado encastillado en visiones tradicionales de conducta y autoridad, y en su choque con la realidad se encuentra con este alumnado postmoderno, el cual resulta difícil manejar, condicionando la comprensión que logran de la tarea educativa. Se da cuenta de que estudiantes y jóvenes han cambiado, logran identificar también que el contexto sociocultural está caracterizado por el influjo de las tecnologías de la información y comunicación y que estas se hacen presentes en el espacio del aula dificultando la tarea; sin embargo, muestra dificultades para visualizar que está llamado a "ser, a la vez, usuario competente de la tecnología e innovadores con la misma y guardianes morales en contra de sus efectos más superficiales y trivializadores" (Hargreaves, 1994, p.107). En estos grupos-como 
actores claves- no se ha generado apertura y respuesta a este cambio de territorio, trama y actores; por el contrario, el predominio de fórmulas y concepciones normativas no le permite una comprensión profunda del trabajo docente.

Finalmente los resultados obtenidos, además de permitir el logro del objetivo propuesto en la investigación, constituyen un importante insumo para revisar, reorientar y consolidar los procesos que desarrolla la institución universitaria respecto a la formación inicial del profesorado. Para ello, en un decidido esfuerzo de bidireccionalidad, el itinerario de formación debe asegurar una mayor alternancia entre la universidad y la escuela, propiciando el desarrollo de espacios de discusión teórica articulados con las problemáticas que experimenta el estudiantado de pedagogía en los centros de práctica y, de esa manera, reconocer y valorar la complejidad que muestra el oficio de maestro y maestra.

\section{Referencias}

Alfaro, T. (2011). Desafío docente: El alumno postmoderno. Revista Digital de Investigación en Docencia Universitaria, 5(1), 54-65. doi: https://doi.org/10.19083/ridu.5.4

Alliaud, A. (2017). Los artesanos de la enseñanza. Acerca de la formación de maestros con oficio. Buenos Aires: Paidós.

Ávalos, B. (2003). La formación docente inicial en Chile. Santiago de Chile: Ministerio de Educación.

Baillauquès, S. (2010). El trabajo de las representaciones en la formación de los maestros. En L. Paquay, M. Altet, É. Charlier y P. Perrenoud (Coords.), La formación profesional del maestro. Estrategias y competencias (pp. 55-87). México: FCE.

Bourdieu, P. y Passeron, J.-C. (1977). La reproducción. Barcelona: LAIA

Carbonneau, M. y Hétu, J.-C. (2010). La formación práctica de los maestros y el nacimiento de una inteligencia profesional. En L. Paquay, M. Altet, É. Charlier y P. Perrenoud (Coords.), La formación profesional del maestro. Estrategias y competencias (pp. 107-138). México: FCE.

Cisternas, T. (2011). La investigación sobre formación docente en Chile. Territorios explorados e inexplorados. Calidad en la educación, 35, 131-164. doi: https://doi.org/10.4067/S0718$\underline{45652011000200005}$

Davini, M. C. (1995). La formación docente en cuestión: Política y pedagogía. Buenos Aires: Paidós.

Diker, G. y Terigi, F. (2008). La formación de maestros y profesores: Hoja de ruta. Buenos Aires: Paidós.

Dubet, F. (2010). Decadència de la institució escolar i confictes entre principis. Barcelona: Fundación Jaume Bofill. 
doi: http://dx.doi.org/10.15359/ree.23-3.8

URL: http://www.una.ac.cr/educare

CORREO: educare@una.cr

Fernández, M. (2001). Educar en tiempos inciertos. Madrid: Morata.

Fernández, M. (2008). El practicum en la construcción del conocimiento profesional docente. En E. Molina, C. Gervais y S. Rittershaussen (Eds.), Vers une conceptualisation de la situation de stage: Explorations internationales (pp.67-89). Montreal: Editions du CRP.

Flick, U. (2007). Introducción a la investigación cualitativa. Madrid: Morata.

Giroux, H. (1996). Educación posmoderna y generación juvenil. Nueva Sociedad, 146, 148-167. Recuperado de http://nuso.org/media/articles/downloads/2554 1.pdf

Hargreaves, A. (1994). Profesorado, cultura y postmodernidad (Cambin los tiempos, cambia el profesorado). Madrid: Morata.

Hernández, R., Fernández, C., y Baptista, M. (2010). Metodología de la investigación. Mexico: McGraw-Hill Education.

Labra, P. (2011). Construcción de conocimiento profesional docente: el caso de la formación en la práctica (Tesis de doctorado). Universidad Academia de Humanismo Cristiano, Santiago, Chile.

Latorre, M. (2006). Nuevas miradas, viejos problemas: Las relaciones entre formación inicial y ejercicio profesional docente. Foro Educativo, 10, 41-63. Recuperado de https://dialnet. unirioja.es/servlet/articulo?codigo $=2292721$

Marcelo, C. (2009). Formalidad e informalidad en el proceso de aprender a enseñar. Revista de Educación, 350, 31-55. Recuperado de https://idus.us.es/xmlui/bitstream/ handle/11441/31362/Formalidad e informalidad.pdf?sequence $=1$

March, M. X. y Orte, C. (2014). La educación social en la sociedad del siglo XXI. (En M. Martí y C. Orte (Coords.), La pedagogía social y la escuela. Los retos socioeducativos de la institución escolar en el siglo XXI (pp. 19-56). Barcelona: Octaedro. Recuperado de https://www. researchgate.net/profile/Carmen Orte/publication/267096018 Pedagogia social y escuela/links/54451ed30cf2f14fb80e99fd/Pedagogia-social-y-escuela.pdf

Montenegro, H. y Fuentealba, R. (2012). Prácticas de enseñanza para la formación de futuros profesores: Propuesta de un modelo para su estudio. III Congreso Internacional sobre Profesorado Principiante e Inserción Profesional a la Docencia. Universidad Autónoma de Chile. Santiago de Chile.

Pérez, A., Martínez, M., Tey. A., Essombra, M., González, T. (2007). Profesorado y otros profesionales de la educación. Madrid: Octaedro. 
Pérez, G. (2007). Investigación cualitativa. Retos e interrogantes. Madrid: La Muralla.

Ruiz, J. I. (2009). Metodología de la investigación cualitativa. Bilbao: Universidad de Deusto.

Sánchez, G. (2016-2017). Los docentes en formación y la comprensión de sus experiencias pedagógicas (Proyecto Interno de Investigación). Talca: Universidad Católica del Maule.

Sayago, Z. B. y Chacón, M. A. (2006). Las prácticas profesionales en la formación docente: Hacia un nuevo diario de ruta. Educere, 10(32), 55-66. Recuperado de http://www.scielo.org.ve/scielo. php?script=sci arttext\&pid=S1316-49102006000100008\&lng=es\&nrm=iso\&tlng=es

Tardif, M. (2004). Los saberes del docente y su desarrollo profesional. Madrid: Narcea.

Tedesco, J. C. y Tenti, E. (2002). Nuevos tiempos y nuevos docentes. Buenos Aires: IIPE, UNESCO. Recuperado de https://www.buenosaires.iiep.unesco.org/sites/default/files/ndocentes tenti-tedesco.pdf

Tiramonti, G. (2004). La trama de la desigualdad educativa. Mutaciones recientes en la escuela media. Buenos Aires: Manantial.

Toffler, A. (1990). El shock del futuro. Barcelona: Plaza y Janes.

Vásquez, A. (2011). La posmodernidad. Nuevo régimen de verdad, violencia metafísica y fin de los metarrelatos. Nómadas. Revista Crítica de Ciencias Sociales y Jurídicas, 29(1), 285-300. doi: https://doi.org/10.5209/rev NOMA.2011.v29.n1.26807 